\title{
Response of the Black Sea methane budget to massive short-term submarine inputs of methane
}

\author{
O. Schmale ${ }^{1}$, M. Haeckel ${ }^{2}$, and D. F. McGinnis ${ }^{2,3}$ \\ ${ }^{1}$ Leibniz Institute for Baltic Sea Research Warnemünde (IOW), Rostock, Germany \\ ${ }^{2}$ Leibniz Institute of Marine Sciences (IFM-GEOMAR), Kiel, Germany \\ ${ }^{3}$ Southern Danish University, Institute of Biology and Nordic Center for Earth Evolution (NordCee), Odense M, Denmark
}

Received: 27 October 2010 - Published in Biogeosciences Discuss.: 15 December 2010

Revised: 18 March 2011 - Accepted: 7 April 2011 - Published: 15 April 2011

\begin{abstract}
A steady state box model was developed to estimate the methane input into the Black Sea water column at various water depths. Our model results reveal a total input of methane of $4.7 \mathrm{Tg} \mathrm{yr}^{-1}$. The model predicts that the input of methane is largest at water depths between 600 and $700 \mathrm{~m}$ (7\% of the total input), suggesting that the dissociation of methane gas hydrates at water depths equivalent to their upper stability limit may represent an important source of methane into the water column. In addition we discuss the effects of massive short-term methane inputs (e.g. through eruptions of deep-water mud volcanoes or submarine landslides at intermediate water depths) on the water column methane distribution and the resulting methane emission to the atmosphere. Our non-steady state simulations predict that these inputs will be effectively buffered by intense microbial methane consumption and that the upward flux of methane is strongly hampered by the pronounced density stratification of the Black Sea water column. For instance, an assumed input of methane of $179 \mathrm{Tg} \mathrm{CH}_{4} \mathrm{~d}^{-1}$ (equivalent to the amount of methane released by 1000 mud volcano eruptions) at a water depth of $700 \mathrm{~m}$ will only marginally influence the sea/air methane flux increasing it by only $3 \%$.
\end{abstract}

\section{Introduction}

For about $30 \mathrm{yr}$ the Black Sea methane cycle has been in the focus of international studies (e.g. Hunt, 1974; Kessler et al., 2006; Reeburgh et al., 1991). The Black Sea water column stratification plays a key role in this complex cycle. Its structure is strongly influenced by the inflow of highly saline water via the Bosphorus and freshwater from rivers, mainly Danube, Dnepr and Dnestr, resulting in a permanent

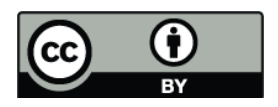

Correspondence to: $\mathrm{O}$. Schmale (oliver.schmale@io-warnemuende.de) pycnocline located at water depths between 100 and $150 \mathrm{~m}$. The lack of sufficient downward supply of dissolved oxygen to counter organic matter fluxes from the highly productive surface waters into the deep waters has resulted in the present anoxic conditions below the pycnocline and has made the Black Sea the world's largest anoxic basin with $\mathrm{CH}_{4}$ concentrations of up to $13 \mu \mathrm{M}$ (Naqvi et al., 2010).

Recent hydroacoustic investigations have shown that active seep sites releasing gas bubbles (consisting mainly of methane) into the water column are widely distributed along the coast, the shelf, shelf edge, and upper slope of the Black Sea (Fig. 1; Dimitrov, 2002; Naudts et al., 2006; Greinert et al., 2006; Nikolovska et al., 2008). Methane is also emitted from submarine mud volcanoes (MVs; Fig. 1). Until today, about 65 MVs have been discovered in the Black Sea. They are located on the Kerch-Taman shelf, the slope off Bulgaria, Ukraine, Russia, Georgia, and Turkey, as well as in the central part of Black Sea (Kruglyakova et al., 2002). The contribution of seeps and MVs to the total Black Sea methane budget, however, is poorly constrained and needs further investigation.

The first Black Sea methane budget by Reeburgh et al. (1991) determined the total water column methane inventory to be $96 \mathrm{Tg}$. Thus, the Black Sea represents the largest marine water reservoir of dissolved methane. According to Reeburgh et al. (1991), the major methane sources are shelf and slope sediments, which are balanced by anaerobic oxidation of methane as the major sink in the anoxic deep water $\left(4.6 \mathrm{Tg} \mathrm{yr}^{-1}\right)$. The second most important sink is the methane flux across the sea/air interface with $0.07 \mathrm{Tg} \mathrm{yr}^{-1}$. The total oxidation rate (oxic and anoxic) of $4.6 \mathrm{Tg} \mathrm{yr}^{-1}$ of $\mathrm{CH}_{4}$ suggests a residence time of about $20 \mathrm{yr}$ for methane. Reeburgh's Black Sea methane budget was modified by Kessler et al. (2006) who estimated the input of methane from seeps and dissociating gas hydrates into the intermediate and deep waters (below $150 \mathrm{~m}$ ) to be $3.6-5.65 \mathrm{Tg} \mathrm{yr}^{-1}$. The regional influence of focused methane gas emissions

Published by Copernicus Publications on behalf of the European Geosciences Union. 


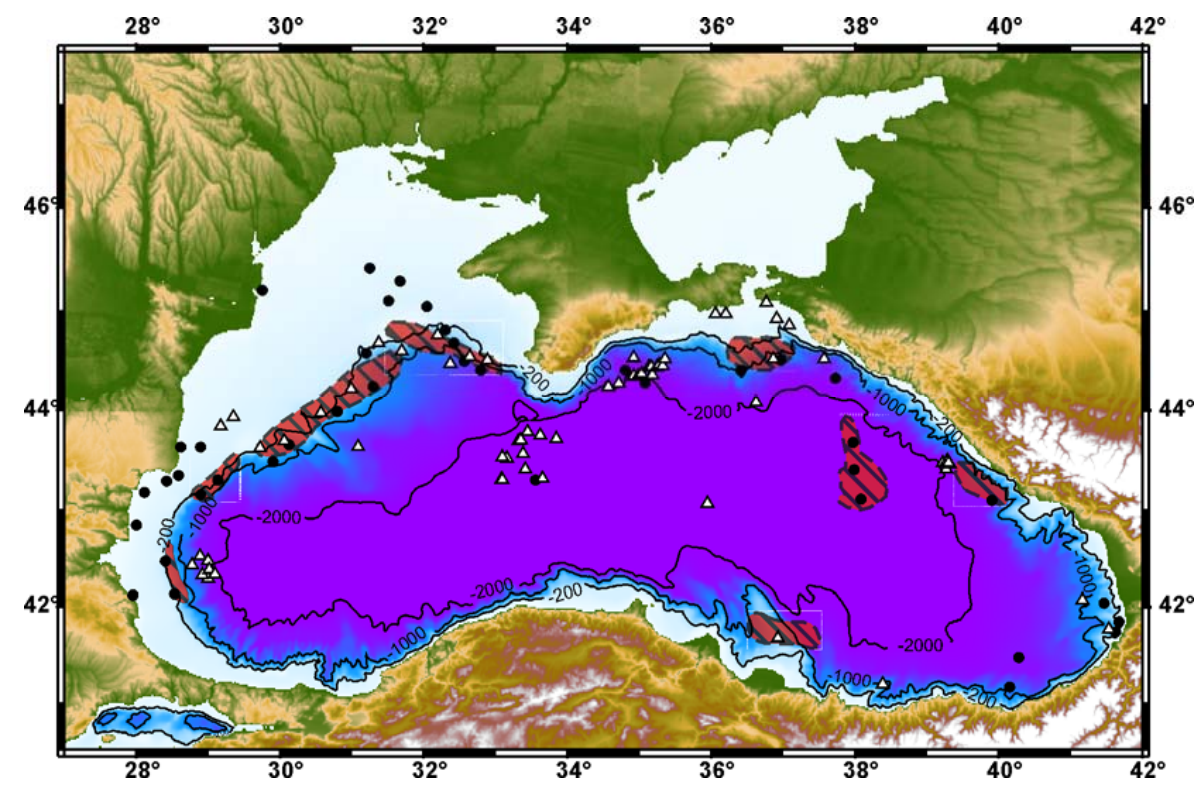

Fig. 1. Map of gas and fluid discharge in the Black Sea. Triangles and dots represent locations of submarine mud volcanoes and areas of intense fluid discharge, respectively. Red areas represent regions of gas seepage and seabed pockmarks. Map is based on a data compilation from Kruglyakova et al. (2004) and Vassilev and Dimitrov (2002).

on the atmospheric methane budget caused by massive methane inputs (e.g. MV eruptions) is studied by Kourtidis et al. (2006), but ignores any effects from the well-documented microbially mediated oxidation of methane in the oxic and anoxic part of the Black Sea water column.

Here, we present a steady state box model with a structure similar to that of Kessler et al. (2006) to determine the Black Sea methane budget. Based on this model we establish a non-steady state model to study the response of the Black Sea methane cycle to massive methane inputs (e.g. caused by MV eruptions or submarine landslides), i.e. we analyse how this would affect the methane water concentrations and the fluxes across the air/sea interface.

\section{Model description}

Two different models were developed: a steady state box model (Model A) to analyse the recent magnitudes of methane inputs into the Black Sea water column and a nonsteady state box model (Model B) to explore the effects of methane injections into different water depths (e.g. by deepwater MV eruptions and landslides at intermediate water depths) on the amount and vertical distribution of methane in the water column as well as on the methane efflux into the atmosphere.

Both box models consist of 20 well-mixed boxes integrating a depth interval of $100 \mathrm{~m}$. Box volumes and areas were calculated based on the GEBCO 1-min global bathymetric grid (http://www.gebco.net/). Both models exchange methane with the atmosphere and include the oxic and anoxic parts of the Black Sea water column with an oxic/anoxic interface located $100 \mathrm{~m}$ below the sea surface. The shelf and coastal waters (water depth $<100 \mathrm{~m}$ ) are not included in our model because the distribution and intensity of methane sources (e.g. river plumes and shallow seep areas) and sinks (e.g. water column methane oxidation and evasion to the atmosphere) are very complex. At the present time, these are poorly constrained in these regions. Methane emitting areas in these shallow areas show only regional influences on the water column methane distribution and are not affecting the open water body of the Black Sea (Schmale et al., 2010).

Water fluxes into and out of the Black Sea were adopted from Özsoy and Ünlüata (1997), but ignore the negligible effects of evaporation, rain, and river inflow on the Black Sea open ocean methane budget. Our model considers a Bosphorus inflow of $300 \mathrm{~km}^{3} \mathrm{yr}^{-1}$ and a similar outflow of $300 \mathrm{~km}^{3} \mathrm{yr}^{-1}$ into the Sea of Marmara. The influx of Bosphorus water is mainly restricted to a water depth between 100 and $500 \mathrm{~m}$ (Oguz and Rozman, 1991), which is balanced by upwelling that is represented by an advective transport (Özsoy and Ünlüata, 1997).

In addition to advection of solutes, the model includes the vertical transfer of methane by eddy diffusion (i.e. $K_{z}$ ). In the nearly stagnant Black Sea deep waters (500-2000 m) the transport of methane is restricted to turbulent diffusion. Eddy diffusion coefficients $\left(K_{z}\right)$ were calculated on the base of CTD profiles to estimate turbulent overturns (Galbraith and Kelley, 1995). 
For the non-steady state Model B, which is used to analyze the response of the Black Sea methane cycle to massive methane injections, the methane input into different water depths was calculated by a gas bubble dissolution model (McGinnis et al., 2006), i.e. a rate-depth profile for the dissolution of rising methane gas bubbles is prescribed. This function predicts the evolving bubble size, gas composition, total bubble rise distance, and dissolution/stripping of five gases $\left(\mathrm{Ar}, \mathrm{CO}_{2}, \mathrm{CH}_{4}, \mathrm{~N}_{2}, \mathrm{O}_{2}\right)$. The model is adapted for the hydrographic conditions of the Black Sea and considers the formation of a hydrate rim around the methane gas bubble within the hydrate stability zone (i.e., below $700 \mathrm{~m}$; Vassilev and Dimitrov, 2002).

To study the sea-air gas exchange in our box model, the surface water box is also connected to the atmosphere. The methane flux across the sea surface $\left(F_{\mathrm{CH}_{4}}\right)$ is calculated based on the sea-air gas exchange model of Wanninkhof (Wanninkhof, 1992) for long-term wind averages.

$F_{\mathrm{CH}_{4}}=k w\left(C_{\mathrm{AE}}-C_{1}\right) A_{1}$

where $k w$ represents the gas transfer velocity across the sea surface, $C_{1}$ is the dissolved methane concentration in the surface water box (box 1; depth interval 0-100 m), $C_{\mathrm{AE}}$ is the theoretical thermodynamic equilibrium concentration between surface waters and the ambient atmosphere, and $A_{1}$ is the surface area. Methane solubility in seawater was calculated following Wiesenburg and Guinasso (Wiesenburg and Guinasso, 1979). Averaged values for salinity, temperature, wind speed, and atmospheric methane concentration were taken from the literature (Table 1).

Methane oxidation rates were calculated based on the dataset published by Reeburgh et al. (1991). They have been shown to depend linearly on the dissolved methane concentration (Ward et al., 1987). Consequently, we applied a first order rate law, assuming that electron acceptors (i.e., $\mathrm{SO}_{4}^{2-}$ and $\mathrm{O}_{2}$ ) are not limiting the microbial methane oxidation rates to derive depth-specific kinetic constants.

$R_{\mathrm{ox}}=k\left[\mathrm{CH}_{4}\right] \Rightarrow k=\frac{R_{\mathrm{ox}}}{\left[\mathrm{CH}_{4}\right]}$

where $k$ is the kinetic constant for methane oxidation, $R_{\mathrm{Ox}}$ the methane oxidation rate, and $\left[\mathrm{CH}_{4}\right]$ the dissolved methane concentration $\left(R_{\mathrm{Ox}}\right.$ and $\left[\mathrm{CH}_{4}\right]$ were taken from Reeburgh et al., 1991). The data from Reeburgh et al. (1991) contain a high-quality dataset with the densest sampling interval available for the central Black Sea. Inhomogeneous oxidation rates within the upper $500 \mathrm{~m}$ result in decreasing $k$ values (box 1-5, Table 1). Below $500 \mathrm{~m}$ water depth (box 6-20) the oxidation rates are homogeneous leading to constant $k$ values.

The detailed parameter values, notations, and references used in the model as well as the transport-reaction equations for each box are listed in Tables 1 and 2 .

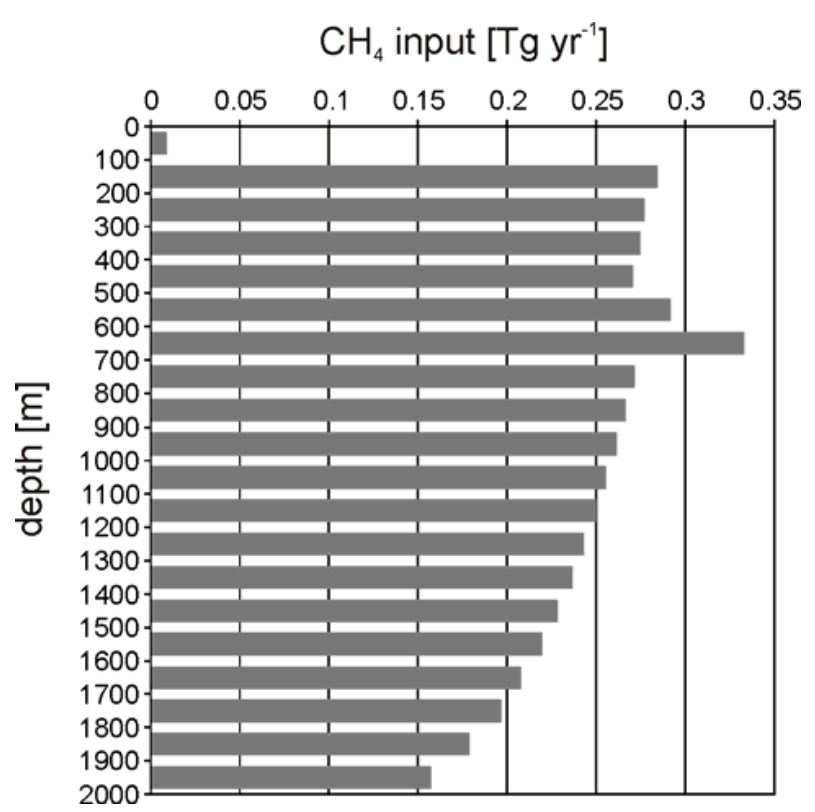

Fig. 2. Methane inputs into different water depths based on steady state Model A.

\section{Results and discussion}

\subsection{Model A: input of methane into the Black Sea water column}

A steady state box model was applied to quantify a depthdependent input of methane to the Black Sea water column. The recent Black Sea methane distribution shows methane concentrations in the nanomolar range (average of $8.7 \mathrm{nM}$; Table 1) at water depth between 0 and $100 \mathrm{~m}$. At intermediate water depths of 100 to $600 \mathrm{~m}$ the methane concentration increases linearly with depth. The deep waters (600$2200 \mathrm{~m}$ ) are characterized by uniform methane concentrations of around $11 \mu \mathrm{M}$ (Reeburgh et al., 1991).

The methane inputs in each box of our Model A were varied until the modelled methane concentrations agreed with the averaged measurements published by Reeburgh et al. (1991; modelled versus measured concentrations are listed for each box in Table 1). Similar to the results published by Kessler et al. (2006) the modelled results displayed in Fig. 2 indicate that most $\mathrm{CH}_{4}$ is entering the Black Sea waters between $600-700 \mathrm{~m}$ water depth $\left(0.33 \mathrm{Tg} \mathrm{CH}_{4} \mathrm{yr}^{-1}\right.$, i.e. $7 \%$ of the total input). The lower boundary of this depth range is close to the stability boundary of methane hydrates (670-700 m; Vassilev and Dimitrov, 2002). Poort et al. (2005) have modelled the regional response of the gas hydrate stability zone to the post glacial flooding and resulting bottom water temperature increase in the Black Sea. They predict that at present a widespread dissociation of gas hydrates is expected to occur at the minimum water depth for 
Table 1. Parameter values, notations, and references.

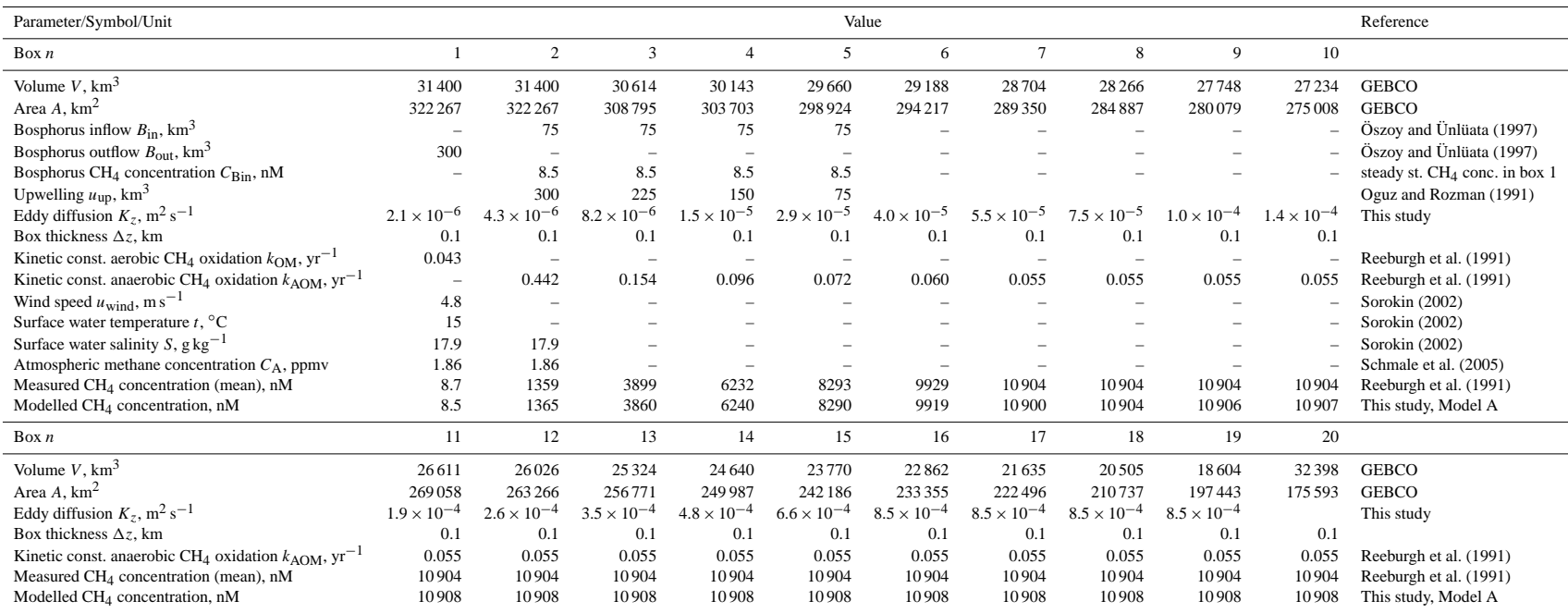

Table 2. Differential equations for each box (abbreviations are listed in Table 1).

\begin{tabular}{ll}
\hline Box & Differential equations \\
\hline 1 & $\frac{\partial C_{n}}{\partial t}=\frac{k w\left(C_{\mathrm{AE}}-C_{n}\right) A_{n}}{V_{n}}-k_{\mathrm{OM}} \cdot C_{n}+\frac{B_{\mathrm{up} n} \cdot C_{n+1}}{V_{n}}-\frac{B_{\mathrm{out}} \cdot C_{n}}{V_{n}}-\frac{K z_{n}\left(C_{n}-C_{n+1}\right) A_{n+1}}{\Delta z_{n} \cdot V_{n}}+R_{\text {in } n}$ \\
$2-4$ & $\frac{\partial C_{n}}{\partial t}=\frac{K z_{n-1}\left(C_{n-1}-C_{n}\right) A_{n}}{\Delta z_{n} \cdot V_{n}}-k_{\mathrm{AOM} n} \cdot C_{n}+\frac{B_{\mathrm{in}} \cdot C_{\text {Bin }}}{V_{n}}-\frac{u_{\mathrm{up} n} \cdot C_{n}}{V_{n}}+\frac{u_{\text {up } n+1} \cdot C_{n+1}}{V_{n}}-\frac{K z_{n}\left(C_{n}-C_{n+1}\right) A_{n+1}}{\Delta z_{n} \cdot V_{n}}+R_{\text {in } n}$ \\
5 & $\frac{\partial C_{n}}{\partial t}=\frac{K z_{n-1}\left(C_{n-1}-C_{n}\right) A_{n}}{\Delta z_{n} \cdot V_{n}}-k_{\mathrm{AOM} n} \cdot C_{n}+\frac{B_{\mathrm{in}} \cdot C_{\mathrm{Bin}}}{V_{n}}-\frac{u_{\text {up } n} \cdot C_{n}}{V_{n}}-\frac{K z_{n}\left(C_{n}-C_{n+1}\right) A_{n+1}}{\Delta z_{n} \cdot V_{n}}+R_{\mathrm{in} n}$ \\
$6-19$ & $\frac{\partial C_{n}}{\partial t}=\frac{K z_{n-1}\left(C_{n-1}-C_{n}\right) A_{n}}{\Delta z_{n} \cdot V_{n}}-k_{\mathrm{AOM} n} \cdot C_{n}-\frac{K z_{n}\left(C_{n}-C_{n+1}\right) A_{n+1}}{\Delta z_{n} \cdot V_{n}}+R_{\mathrm{in} n}$ \\
20 & $\frac{\partial C_{n}}{\partial t}=\frac{K z_{n-1}\left(C_{n-1}-C_{n}\right) A_{n}}{\Delta z n \cdot V_{n}}-k_{\mathrm{AOM} n} \cdot C_{n}+R_{\text {in } n}$ \\
\hline
\end{tabular}

$R_{\text {in } n}$ represents the methane flux into each box.

hydrate stability. The model results imply that gas hydrate dissociation at the Black Sea continental slopes may take place and serve as an important methane source to intermediate waters. However, so far only a few active seep sites influencing the methane concentrations in the water column have been discovered in this specific depth range (Fig. 1). Hydroacoustic seep detection along the slope of the NW Black Sea indicates that the minimum depth of gas hydrate stability is not characterized by a higher-than-average number of seep sites (Naudts et al., 2006).

In contrast to previously published Black Sea methane models, our model also describes the methane cycle in the upper $100 \mathrm{~m}$ of the Black Sea water column. The model predicts that diffusive and advective transports are not sufficient to maintain the average surface water methane concentration of $8.7 \mathrm{nM}$ observed by Reeburgh et al. (1991); the modelled concentration without additional surface water input is $5.9 \mathrm{nM}$. An additional input of $0.009 \mathrm{Tg} \mathrm{yr}^{-1}$ of $\mathrm{CH}_{4}$ is needed to reach a surface water methane concentration similar to the one published by Reeburgh et al. (1991).
This open ocean methane source at shallow water depths is provided by microbial subsurface methane generation taking place in zooplankton guts, the oxygen-deficient interior of particles (e.g. fecal pellets), or under phosphate limiting conditions (Damm et al., 2010; Karl et al., 2008). Subsurface methane maxima together with light ${ }^{13} \mathrm{CH}_{4}$ anomalies have been observed in the upper water column of the Black Sea by Schmale et al. (2010) indicating that this methane production occurs in the oxygenated water column. The limited methane transport across the pycnocline by eddy diffusion and upwelling stresses that the subsurface methane generation is crucial for the methane flux across the sea surface in Black Sea open waters. However, the subsurface methane production rate is poorly constrained by our model, because the methane source term in the upper $100 \mathrm{~m}$ is highly correlated to rate of sea-air gas exchange. Depending on the approach used to parameterize the gas transfer velocity $(k w)$ the sea-air flux estimates can show large variations (Wanninkhof et al., 2009). 
Overall, the basin-wide $\mathrm{CH}_{4}$ input of $4.7 \mathrm{Tg} \mathrm{yr}^{-1}$ calculated by our Model $\mathrm{A}$ is similar to the estimate published by Kessler et al. (2006; i.e. 3.6-5.65 $\mathrm{Tg} \mathrm{yr}^{-1}$ ) and identical with the sediment production calculated by Reeburgh et al. (1991). The good agreement between these different datasets represents an indirect validation of our steady state model.

\subsection{Model B: influence of massive short-term methane injections on the Black Sea methane budget}

Based on the structure of Model A a non-steady state model was applied to predict the effects of massive short-term methane injections on the methane distribution in the Black Sea water column. Two scenarios are discussed: (Model B1) the release of methane from numerous Black Sea MVs in the abyssal plain at about $2000 \mathrm{~m}$ water depths (Fig. 1), and (Model B2) the injection of methane at the gas hydrate stability boundary where hydrate dissociation may take place and submarine landslides could be expected $(670-700 \mathrm{~m}$; Vassilev and Dimitrov, 2002; Poort et al., 2005).

The approach was to separately increase the methane input to these two water depths (represented by boxes 7 and 20 ; i.e. depth intervals of 600-700 $\mathrm{m}$ and 1900-2000 m, respectively) and to simulate the evolution of methane concentration in the Black Sea water column and the resulting flux of methane across the sea surface until a steady state was reached.

It is difficult to constrain the methane release from MV eruptions or submarine landslides since no direct gas flux measurements are available from these events. In terms of MV eruptions a few estimates exist implying that gas fluxes are on the order of $10^{7}$ to $10^{10} \mathrm{~m}^{3}$ (STP = at standard pressure and temperature conditions, i.e., $25^{\circ} \mathrm{C}$ and 1 bar) over several days (Milkov et al., 2003, and references therein). In our model, we use a number which is based on gas flux records during strong eruptions of onshore mud volcanoes in Azerbaijan $\left(2.5 \times 10^{8} \mathrm{~m}^{3} \mathrm{CH}_{4}\left(=179 \mathrm{Gg}\right.\right.$ or $\left.1.1 \times 10^{10} \mathrm{~mol}\right)$ per eruptive MV event; Dadashev, 1963; a number also used by Milkov et al. (2003) to estimate the global gas flux from eruptive MVs). To model the effect of massive shortterm methane inputs we use a fictive number of $179 \mathrm{Tg} \mathrm{CH}_{4}$ (equivalent to the amount of methane released by $1000 \mathrm{MV}$ eruptions) released within a day. We also assume that these kinds of massive sedimentary gas inputs will be characterized by the release of free gas (i.e. gas bubbles). To describe the input of methane into different water depths by ascending gas bubbles, we applied the gas bubble dissolution model of McGinnis et al. (2006). The largest bubbles observed in the Black Sea are around $18 \mathrm{~mm}$ in diameter (McGinnis et al., 2006, and references therein). This most likely represents the upper size limit, as larger bubbles may have a tendency to break apart during their rise and are transported as smaller bubbles with faster dissolution and gas exchange (McGinnis et al., 2006). For our model run we use an initial bubble diameter of $20 \mathrm{~mm}$, hypothesizing that an eruptive gas release would rather result in the liberation of large bubbles.

\subsubsection{Model B1: methane input at $2000 \mathrm{~m}$ water depth}

The simulation of Model B1 was initiated with the steady state methane concentrations obtained with Model A. Further, we assume a methane release of $179 \mathrm{Tg}$ of $\mathrm{CH}_{4}$ at $2000 \mathrm{~m}$ water depth over an eruptive phase of one day (e.g. eruptions of $1000 \mathrm{MVs}$ ). Proposing that the gas exclusively consists of methane, the eruptions will increase the input of methane in box 20 (depth interval 2000-1900m) at a rate of $10.9 \mathrm{Gg} \mathrm{km}^{-3} \mathrm{~d}^{-1}$. The bubble model of McGinnis et al. (2006) predicts that within the hydrate stability zone (i.e., below $700 \mathrm{~m}$ water depth) the bubble dissolution rate is slowed down by the formation of a gas hydrate rim around the bubble (Fig. 3a). After passing the stability boundary of gas hydrates, the model assumes that the hydrate skin disappears instantly, resulting in faster bubble dissolution rates and increasing methane inputs.

For this massive methane input the model results suggest that it takes about $200 \mathrm{yr}$ to return to the previous steady state methane concentrations. In this run the initial methane input in box $20(1900-2000 \mathrm{~m})$ results in a concentration increase within this box which is about fivefold higher than the concentration derived from our steady state calculations (Model A, Fig. 4a). The methane input caused by the rapid dissolution of gas bubbles above the hydrate stability zone leads to a concentration increase in box 7 (600-700 m) which is about seven times higher than the steady state concentration. However, the large methane input is effectively buffered by microbial methane consumption and pronounced water column stratification leading to a constantly decreasing influence on the methane concentrations in the overlying boxes. The model shows that the influence of such a major event on the surface water methane concentration is negligible and only leads to a 2-\% increase in the sea/air methane flux.

To test if the concentrations of $\mathrm{SO}_{4}^{2-}$ in the anoxic Black Sea waters are high enough to compensate for the high $\mathrm{CH}_{4}$ input of the MV eruption scenario (i.e. $1.1 \times 10^{13} \mathrm{~mol}$ of $\mathrm{CH}_{4}$ for $1000 \mathrm{MV}$ eruptions), we calculated the total amount of sulfate below $100 \mathrm{~m}$ water depth. The balance shows that the total amount of sulfate of about $9 \times 10^{18}$ mol can easily compensate for the maximum methane injections. The annual sulfate input from the Bosphorus $\left(0.95 \times 10^{13} \mathrm{~mol}\right)$ is already of the same order of magnitude.

\subsubsection{Model B2: methane input at $700 \mathrm{~m}$ water depth}

Our second case study focused on the inspection of a methane release to intermediate water depths (e.g. catastrophic submarine landslide) and its influence on the water column methane distribution and the subsequent atmospheric emission. Also, this model run was initiated with steady state methane concentrations calculated in Model A and assumes 

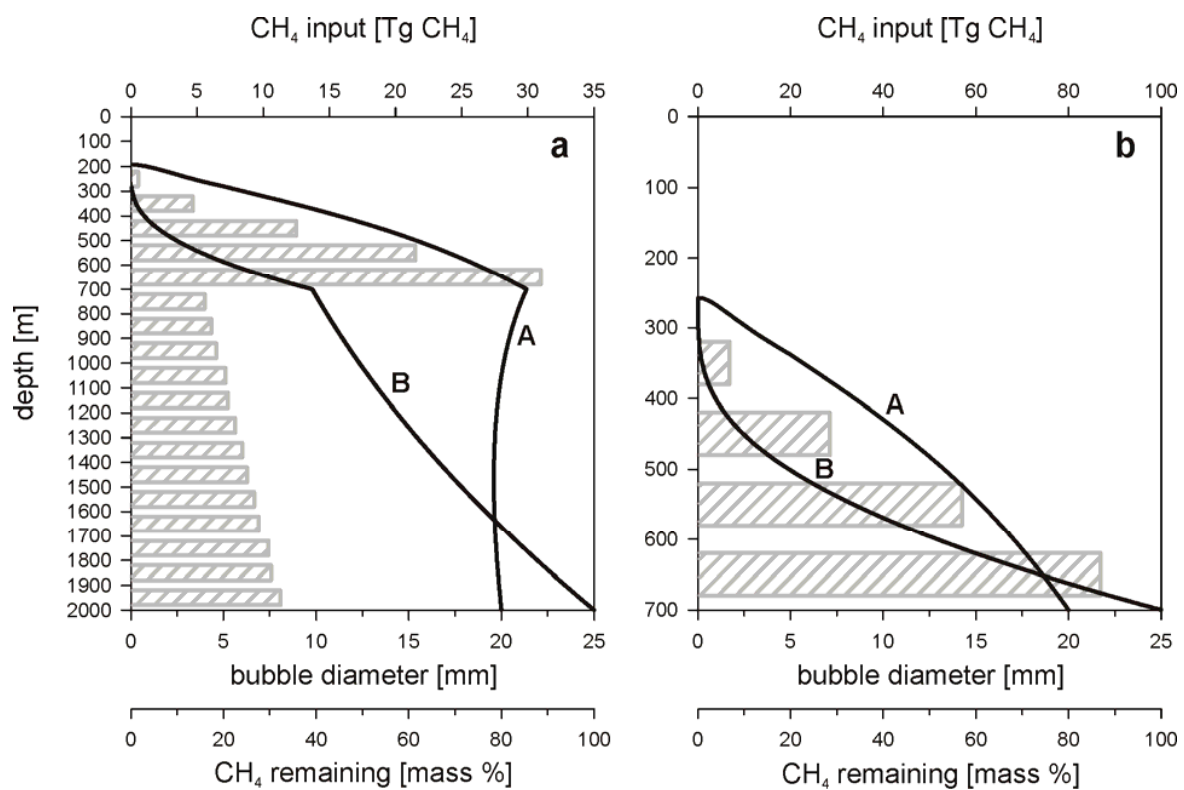

Fig. 3. Inputs of methane into different water depths after a release of $179 \mathrm{Tg} \mathrm{d}^{-1}$ of $\mathrm{CH}_{4}$ at (a) $2000 \mathrm{~m}$ and (b) $700 \mathrm{~m}$ water depth. The input function is based on a bubble model predicting the (A) evolution of the bubble size and (B) the fraction of methane remaining in the uprising bubble (McGinnis et al., 2006). Note the different depth scales.
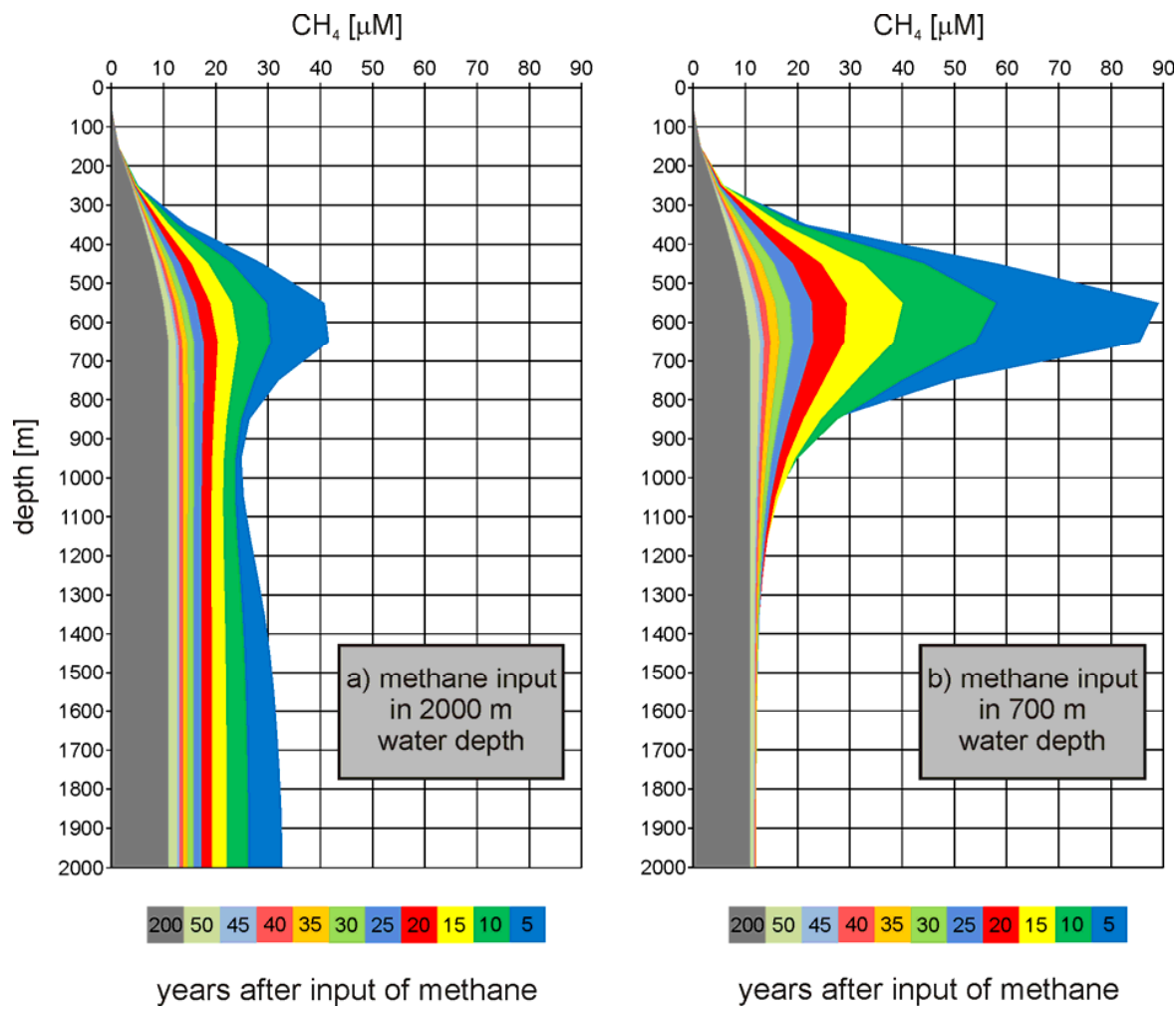

Fig. 4. $\mathrm{CH}_{4}$ evolution over time after an initial input of $179 \mathrm{Tg}$ of $\mathrm{CH}_{4}$. The left panel (a) represents the dissolved methane distribution after an input at $700 \mathrm{~m}$ water depth. The right panel (b) shows the distribution after an input at $2000 \mathrm{~m}$ water depth. The colour scale indicates the years after the input event. The gray area represents the final steady state methane concentration in the Black Sea water column. 
a methane release of $179 \mathrm{Tg}$ of $\mathrm{CH}_{4}$ at $700 \mathrm{~m}$ water depth over a time span of one day. Such an event will increase the input of methane to box 7 (depth interval 600-700 m) to $6.2 \mathrm{Gg} \mathrm{km}^{-3} \mathrm{~d}^{-1}$. In contrast to Model B1 methane is released above the hydrate stability zone resulting in a constantly decreasing bubble size and methane input during the bubble ascent (Fig. 3b).

After the injection of gas, the initial methane concentration in box 7 increases up to $200000 \mathrm{nM}$ (about 20 times higher than the steady state concentration calculated in Model A). The relaxation time needed for the system to return to previous steady state concentrations is about $200 \mathrm{yr}$. Also, this study shows that methane is efficiently consumed microbially and that the exchange between individual boxes is strongly hampered, resulting in a limited transport of methane towards the sea surface (Fig. 4b). The slightly elevated surface water methane concentration increases the methane emission across the sea surface by only $3 \%$.

Kessler et al. (2011) studied the response of the water column methane cycle after the Deepwater Horizon oil spill in the Gulf of Mexico in the year 2010. The authors registered a rapid feedback of aerobic methanotrophic bacteria indicated by an increase in population size and methane oxidation rate constant ( $k_{\mathrm{OM}}$ amplification by a factor of 100). Such a bloom in the anoxic waters of the Black Sea is rather unlikely because of the slow growth rate of methane oxidizing consortia (doubling time in the order of several months, Nauhaus et al., 2007). However, over the predicted $200 \mathrm{yr}$ lifetime of this methane perturbation, a doubling time of several months would be viewed as a relatively instantaneous bloom. Thus, to simulate the lifetime of methane perturbation under different rate constants we increased $k$ by a factor of 2, 5, 10 and 100 in each box. We examined the lifetime of methane perturbation in box 6 (500-600 $\mathrm{m}$ water depth), which shows the strongest increase in methane concentration (Fig. 4b). The results displayed in Fig. 5 indicate that the lifetime of methane decreases from 190 to $0.4 \mathrm{yr}$ using $k$ values reported by Reeburgh et al. (1991; Table 1) and an assumed increase of $k$ by a factor of 100 .

\section{Conclusion and outlook}

Our model predicts that massive short-term injections of methane will be effectively buffered in the Black Sea water column. Even if the gas is liberated at intermediate water depths methane transport to the surface and thus emission across the sea/air interface is strongly reduced by microbial methane consumption and the hydrographic stratification of the Black Sea. It should be highlighted that we employ a vertical 1-dimensional box model which inherently assumes homogenous methane emission over each depth interval. Further investigation is required for the appropriate extrapolation of intense localized emissions (such as pure methane emissions producing focused two-phase plumes (Kourtidis et

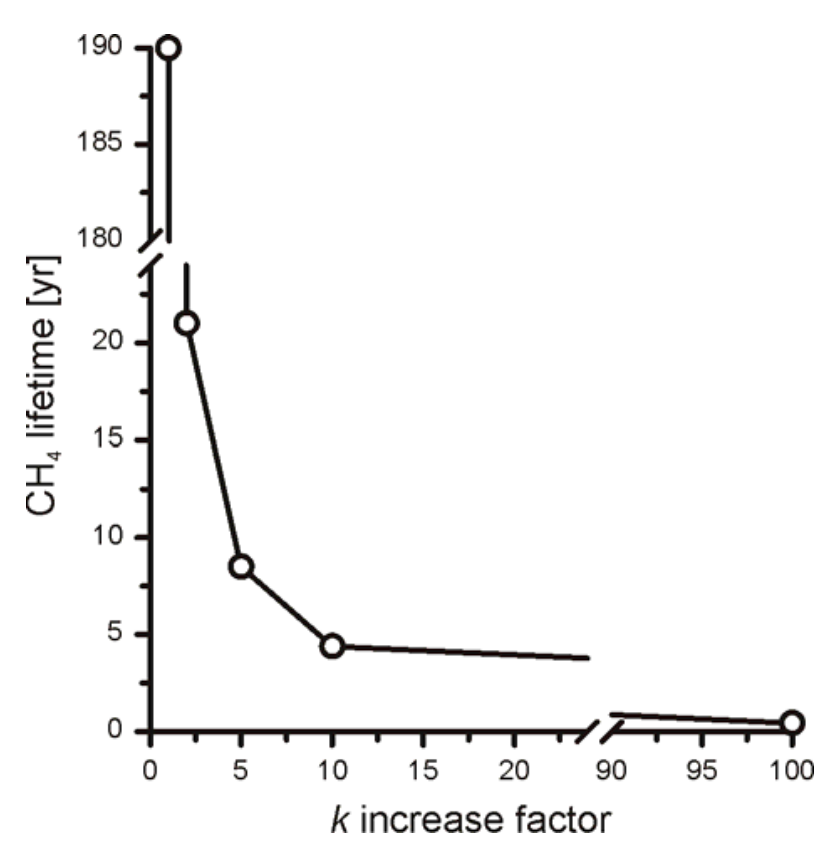

Fig. 5. Lifetime of methane perturbation as a function of the increase factor of $k$. Model runs were performed for factors of 2, 5, 10 , and 100. The results of box 6 are displayed from simulations with Model B2.

al., 2006; Leifer and Patro, 2002) as well as gas and oil emissions forming deepwater and mid-depth plumes (Socolofsky and Adams, 2005) to these larger integrated spatial scales.

Acknowledgements. We thank Gregor Rehder, Robin Keir and Christian Holzner for comments and suggestions which considerably helped to improve the manuscript. This manuscript was improved by the constructive review of J. D. Kessler.

Edited by: S. W. A. Naqvi

\section{References}

Dadashev, F. G.: Hydrocarbon gases of mud volcanoes of Azerbaijan, Azerneshr, Baku, 1963.

Damm, E., Helmke, E., Thoms, S., Schauer, U., Nöthig, E., Bakker, K., and Kiene, R. P.: Methane production in aerobic oligotrophic surface water in the central Arctic Ocean, Biogeosciences, 7, 1099-1108, doi:10.5194/bg-7-1099-2010, 2010.

Dimitrov, L.: Contribution to atmospheric methane by natural seepages on the Bulgarian continental shelf, Cont. Shelf Res., 22, 2429-2442, 2002.

Galbraith, P. S. and Kelley, D. F.: Identifying overturns in CTD profiles, J. Atmos. Ocean. Tech., 13, 688-702, 1995.

Greinert, J., Artemov, Y., Egorov, V. N., De Batist, M., and McGinnis, D.: 1300-m-high rising bubbles from mud volcanoes at 2080 $\mathrm{m}$ in the Black Sea: Hydroacoustic characteristics and temporal variability, Earth Planet. Sci, Lett., 244, 1-15, 2006. 
Hunt, J. M.: Hydrocarbon Geochemistry of Black Sea, in: The Black Sea - Geology, Chemistry, and Biology, edited by: Degens, E. T. and Ross, D. A., The American Association of Petroleum Geologists, 499-504, 1974.

Karl, D. M., Beversdorf, L., Bjorkman, K. M., Church, M. J., Martinez, A., and Delong, E. F.: Aerobic production of methane in the sea, Nat. Geosci., 1, 473-478, 2008.

Kessler, J. D., Reeburgh, W. S., Southon, J., Seifert, R., Michaelis, W., and Tyler, S. C.: Basin-wide estimates of the input of methane from seeps and clathrates to the Black Sea, Earth Planet. Sci. Lett., 243, 366-375, 2006.

Kessler, J. D., Valentine, D. L., Redmond, M. C., Du, M., Chan, E. W., Mendes, S. D., Quiroz, E. W., Villanueva, C. J., Shusta, S. S., Werra, L. M., Yvon-Lewis, S. A., and Weber, T. C.: A Persistent Oxygen Anomaly Reveals the Fate of Spilled Methane in the Deep Gulf of Mexico, Science, 331, 312-315, doi:10.1126/science.1199697, 2011.

Kourtidis, K., Kioutsioukis, I., McGinnis, D. F., and Rapsomanikis, S.: Effects of methane outgassing on the Black Sea atmosphere, Atmos. Chem. Phys., 6, 5173-5182, doi:10.5194/acp-6-51732006, 2006.

Kruglyakova, R., Gubanov, Y., Kruglyakov, V., and Prokoptsev, G.: Assessment of technogenic and natural hydrocarbon supply into the Black Sea and seabed sediments, Cont. Shelf Res., 22, 23952407, 2002.

Kruglyakova, R. P., Byakov, Y. A., Kruglyakova, M. V., Chalenko, L. A., and Shevtsova, N. T.: Natural oil and gas seeps on the Black Sea floor, Geo-Mar. Lett., 24, 150-162, 2004.

Leifer, I. and Patro, R.: The bubble mechanism for transport of methane from the shallow seabed to the surface: a review and sensitivity study, Cont. Shelf Res., 22, 2409-2428, 2002.

McGinnis, D. F., Greinert, J., Artemov, Y., Beaubien, S. E., and Wüest, A.: Fate of rising methane bubbles in stratified waters: How much methane reaches the atmosphere?, J. Geophys. Res., 111, C09007, doi:10.1029/2005jc003183, 2006.

Milkov, A. V., Sassen, R., Tatiyana, V., Apanasovich, V., and Dadashev, G.: Global gas flux from mud volcanoes: A significant source of fossil methane in the atmosphere and the ocean, Geophys. Res. Lett., 30, 1037, doi:10.1029/2002GL016358, 2003.

Naqvi, S. W. A., Bange, H. W., Farías, L., Monteiro, P. M. S., Scranton, M. I., and Zhang, J.: Marine hypoxia/anoxia as a source of $\mathrm{CH}_{4}$ and $\mathrm{N}_{2} \mathrm{O}$, Biogeosciences, 7, 2159-2190, doi:10.5194/bg7-2159-2010, 2010.

Naudts, L., Greinert, J., Artemov, Y., Staelens, P., Poort, J., Van Rensbergen, P., and De Batist, M.: Geological and morphological setting of 2778 methane seeps in the Dnepr paleo-delta, northwestern Black Sea, Mar. Geol., 227, 177-199, 2006.
Nauhaus, K., Albrecht, M., Elvert, M., Boetius, A., and Widdel, F.: In vitro cell growth of marine archaeal-bacterial consortia during anaerobic oxidation of methane with sulfate, Environ. Microbiol., 9, 187-196, 2007.

Nikolovska, A., Sahling, H., and Bohrmann, G.: Hydroacoustic methodology for detection, localization, and quantification of gas bubbles rising from the seafloor at gas seeps from the eastern Black Sea, Geochem. Geophys. Geosyst., 9, Q10010, doi:10.1029/2008gc002118, 2008.

Oguz, T. and Rozman, L.: Characteristics of the Mediterranean underflow in the southwestern Black Sea continental shelf/slope region, Oceanol. Acta, 14, 433-444, 1991.

Özsoy, E. and Ünlüata, Ü.: Oceanography of the Black Sea: a review of some recent results, Earth-Sci. Rev., 42, 231-272, 1997.

Poort, J., Vassilev, A., and Dimitrov, L.: Did postglacial catastrophic flooding trigger massive changes in the Black Sea gas hydrate reservoir?, Terra Nova, 17, 135-140, 2005.

Reeburgh, W. S., Ward, B. B., Whalen, S. C., Sandbeck, K. A., Kilpatrick, K. A., and Kerkhof, L. J.: Black Sea methane geochemistry., Deep-Sea Res., 38, 1189-1210, 1991.

Schmale, O., Beaubien, S. E., Rehder, G., Greinert, J., and Lombardi, S.: Gas seepage in the Dnepr paleo-delta area (NW-Black Sea) and its regional impact on the water column methane cycle, J. Mar. Syst., 80, 90-100, 2010.

Socolofsky, S. A. and Adams, E. E.: Role of Slip Velocity in the Behavior of Stratified Multiphase Plumes, J. Hydraul. Eng.-ASCE, 131, 273-282, doi:10.1061/(ASCE)07339429(2005)131:4(273), 2005.

Sorokin, Y. I.: The Black Sea: Ecology and Oceanography, Biology of Inland Waters, edited by: Martens, K., Backhuys Publishers, Leiden, 2002.

Vassilev, A. and Dimitrov, L.: Spatial and quantity evaluation of the Black Sea gas hydrates, Russian Geology and Geophysics, 43, 637-649, 2002.

Wanninkhof, R.: Relationship between wind speed and gas exchange over the ocean, J. Geophys. Res., 97, 7373-7382, 1992.

Wanninkhof, R., Asher, W., Ho, D. T., Sweeney, C., and McGillis, W. R.: Advances in quantifying air-sea gas exchange and environmental forcing, Annu. Rev. Mar. Sci., 1, 213-244, 2009.

Ward, B. B., Kilpatrick, K. A., Novelli, P. C., and Scranton, M. I.: Methane oxidation and methane fluxes in the ocean surface layer and deep waters, Nature, 327, 226-229, 1987.

Wiesenburg, D. A., Norman, L., and Guinasso, J.: Equilibrium solubilities of methane, carbon monoxide, and hydrogen in water and sea water, J. Chem. Eng. Data, 24, 356-360, 1979. 